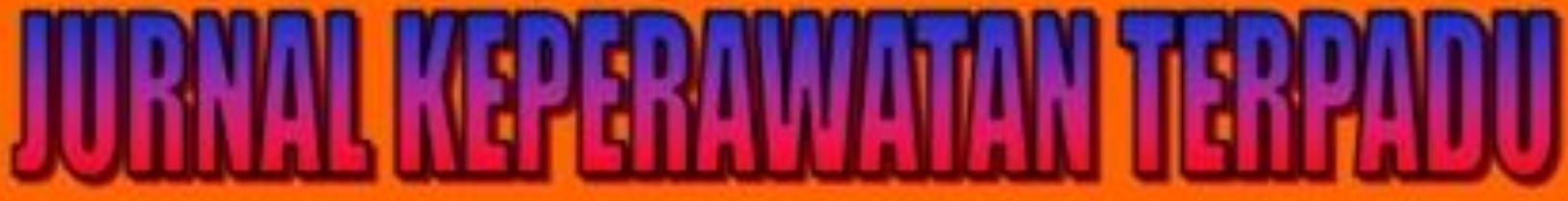

\section{Integrated Nursing Journal}

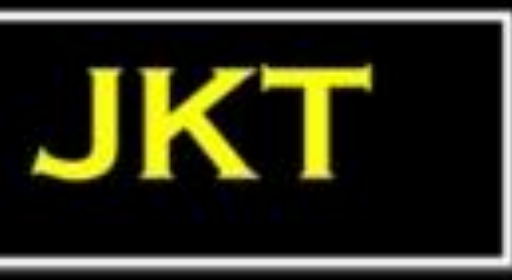

\section{p-ISSN: 2406-9698 (Print) e-ISSN: 2685-0710 (Online)}

\section{Vol. 2 No. 1 April 2020}

\section{KEMENTERIAN KESEHATAN RI}

\section{POLTEKKES MATARAM JURUSAN KEPERAWATAN}

Jalan Kesehatan V/10 Mataram NTB - http://jkt.poltekkes-mataram.ac.id 


\section{Vol. 2 No. 1 April 2020}

\section{Editorial Team}

\section{Editor-in-Chief}

Moh. Arip, Jurusan Keperawatan Poltekkes Kemenkes Mataram, Indonesia

\section{Editorial Board}

1. Mr. Frans Judea Samosir, Universitas Prima Indonesia, Indonesia

2. Baiq Kirana Kitna, Jurusan Keperawatan, Poltekkes Kemenkes Mataram, Indonesia

3. Irwan Budiana, Jurusan Keperawatan, Poltekkes Kemenkes Kupang, Indonesia

4. dr. Baskoro Tri Laksono, RS. Biomedika Mataram, Indonesia

5. Sitti Rusdianah, Jurusan Keperawatan, Poltekkes Kemenkes Mataram, Indonesia

6. Mira Utami Ningsih, Jurusan Keperawatan, Poltekkes Kemenkes Mataram, Indonesia

\section{Alamat Redaksi:}

Jurusan Keperawatan Mataram Poltekkes Kemenkes Mataram Kampus B

Jl. Kesehatan V No.10 Pajang Timur-Mataram NTB-Indonesia, 83127

Telepon: +62 370-621383

Fax: +62 370-631160

Email: jurnalkeperawatanterpadu2019@gmail.com

Laman: http://jkt.poltekkes-mataram.ac.id/index.php/home/index 


\section{Vol. 2, No. 1, April 2020}

\section{DAFTAR ISI}

Pengaruh Self Hypnosis Terhadap Respon Cemas Mahasiswa

Pada Ujian Tahap Akhir Program Di STIKes Buana Husada Ponorogo

Yudha Anggit Jiwantoro, Afifa Ika Kridawati, Danies Tunjung Pratiwi

Efektifitas Tepid Water Sponge Terhadap Penurunan Suhu Tubuh Pada Anak Dengan Masalah Keperawatan Hipertermia: Studi Kasus

Emy Mulyani, Nur Eni Lestari

Perilaku Pencegahan Penyakit Tidak Menular Pada Remaja Ambon

Hamdan Hariawan, Martini Tidore, Greeny Z. Rahakbau

Pengetahuan dan Sikap Perawat Berhubungan dengan Pelaksanaan Patient

Safety

Elisa Sulistia Fitri, Kusnanto, Herdina Maryanti

Efektivitas Art Therapy terhadap Pengetahuan dan Praktik Pemeliharaan Kesehatan Gigi pada Anak Usia Prasekolah

Linda Widyarani, Wiwi Kustio Priliana, Cecilya Kustanti

Konsep Diri Remaja Yang Mengalami Bullying

Puji Lestari, Liyanovitasari

Pengaruh Senam Tai Chi Terhadap Peningkatan Kualitas Tidur Lansia Di Balai Sosial Lanjut Usia Mandalika

Fathaillah Liestanto, Dina Fitriana

Hubungan Komunikasi Terapeutik Perawat Dengan Tingkat Kecemasan

Pasien Hemodialisa Di RSUD Dr Harjono Ponorogo

Ervan Nur Cholis, Rumpiati Rumpiati, Ike Sureni

Upaya Mengatasi Nyeri Post Op Sectio Cesaria Melalui Foot Massage Therapy Diruang Nifas RSUD Kota Mataram

Masadah, Cembun, Ridawati Sulaeman

Peningkatan Pemberdayaan Keluarga Melalui PINKESGA (Paket Informasi Keluarga) Kehamilan Dalam Mengambil Keputusan Merawat Ibu Hamil Mardiatun, Dewi Purnamawati, Ely Mawaddah
Page

$1-6$

Page

$7-14$

Page

$15-21$

Page

22-28

Page

29-39

Page

40-46

Page

$47-53$

Page

54-63

Page

$64-70$

Page

$70-78$ 


\title{
Pengaruh Self Hypnosis Terhadap Respon Cemas Mahasiswa Pada Ujian Tahap Akhir Program Di STIKes Buana Husada Ponorogo
}

\author{
Yudha Anggit Jiwantoro ${ }^{1}$, Afifa Ika Kridawati ${ }^{2}$, Danies Tunjung Pratiwi ${ }^{3}$ \\ 1,2,3 Prodi S1 Ilmu Keperawatan, STIKES Buana Husada Ponorogo, Indonesia
}

\begin{abstract}
Abstrak
Pembelajaran praktik klinik keperawatan merupakan masa transisi dari situasi belajar dikelas ke situasi pelayanan yang nyata, hal ini sangat memungkinkan mahasiswa mengalami kecemasan yang tinggi. Kurangnya pengalaman klinik, dosen yang disiplin, takut membuat kesalahan merupakan situasi yang dapat memproduksi adanya kecemasan mahasiswa. Self hypnosis adalah suatu metode komunikasi persuasif yang digunakan untuk melakukan perubahan kognitif, sikap dan perilaku dengan memasuki wilayah sub consious dalam pikiran manusia. Tujuan penelitian ini menganalisa pengaruh pemberian terapi self hypnosis terhadap respon cemas mahasiswa pada ujian tahap akhir program. Desain penelitian ini pra eksperimen dengan one group pre test post test design. Sampel penelitian ini adalah mahasiswa S1 Keperawatan STIKes Buana Husada sebanyak 22 orang dengan teknik total sampling. Instrumen yang digunakan kuesioner HARS dan modul self hypnosis, dengan analisa uji wilcoxon. Hasil penelitian ada pengaruh self hypnosis terhadap respon cemas mahasiswa. Kesimpulan penelitian ini pemberian self hypnosis berhasil secara signifikan menurunkan angka kecemasan mahasiswa.
\end{abstract}

Kata Kunci : self hypnosis; cemas; ujian akhir program

\section{The Influence Of Self Hypnosis Against Anxious Response A Student On The Test The Final Phase Of The Stikes Buana Husada Ponorogo}

\begin{abstract}
Learning nursing clinical practice is the transition from classroom learning situation to a situation of real service, it is very possible student experience high anxiety. The lack of clinical experience, faculty discipline, fear of making mistakes is a situation that can produce anxiety students. Self hypnosis is a persuasive communication method used to perform cognitive changes, attitudes and behavior by entering the sub-consious in the human mind. The purpose of this study to analyze the effect of self hypnosis therapy against anxiety responses of students at the end of the test phase of the program. The study design is a pre experiment with one group pretest posttest design. The sample was STIKes Buana S1 Nursing students 22 people with a total sampling technique. Instruments used questionnaires Hars and module self hypnosis, the Wilcoxon test analysis. The research result is no effect of self hypnosis influence on the response of anxious students. The conclusion of this study self hypnosis administration succeeded in significantly reducing the number of student anxiety.
\end{abstract}

Keywords: self hypnosis; anxious; final program examination

\section{PENDAHULUAN}

Gangguan kecemasan tidak saja memperlihatkan gejala - gejala perilaku kecemasan, tetapi dapat juga memperlihatkan gejala perilaku fobia dan obsesif (Tomb, 2004). Gangguan kecemasan juga merupakan pemicu terhadap gangguan depresi mayor dan merupakan risiko yang lebih besar bagi upaya percobaan bunuh diri pada lebih kurang $40 \%$ kasus depresi mayor. Menurut data National 
Institute of Mental Health (2005), di Amerika Serikat terdapat 40 juta orang mengalami gangguan kecemasan pada usia 18 tahun sampai pada usia lanjut. Gangguan kecemasan merupakan gangguan kejiwaan yang menempati peringkat ke empat dari semua masalah gangguan kejiwaan di Amerika.

Praktik klinik keperawatan bagi mahasiswa tingkat satu ini merupakan pengalaman pertama kali masuk ke rumah sakit untuk malaksanakan pembelajaran praktik klinik yang harus menyesuaikan dengan lingkungan yang baru, harus melakukan interaksi dengan pasien dan keluarga, dan bekerja sama dengan team kesehatan lain yang semua itu masih asing baginya (Masoumi \& Sharif, 2005). Kurangnya pengalaman klinik, dosen yang tegas, takut membuat kesalahan merupakan situasi yang dapat memproduksi adanya kecemasan mahasiswa. Terlebih pada penelitian ini mahasiswa baru pertama untuk melakukan ujian tahap praktek, sehingga faktor kecemasan akan kegagalan lebih tinggi.

Self hypnosis adalah suatu metode komunikasi persuasif yang digunakan untuk melakukan perubahan kognitif, sikap dan perilaku dengan memasuki wilayah sub consious dalam pikiran manusia. Menurut (Gunawan, 2005). Kondisi relaksasi yang terjadi akibat perlakuan dengan hypnosis dapat memicu perubahan gelombang otak dimana pada kondisi hypnosis, otak akan memasuki gelombang alpha sampai tetha, pada keadaan ini pikiran menjadi sangat rilek, frekuensi gelombangnya menjadi lebih ritmis dan teratur sehingga efek yang timbul pada otak adalah diproduksinya neurotransmitter seperti endorfin, GABA, enkefalin dan beberapa neurotransmitter lain yang berfungsi untuk menurunkan kondisi cemas sekaligus menimbulkan efek relaksasi.

Self Hypnosis selain dikenal sebagai agent anti kecemasan yang kuat, juga mampu menimbulkan efek relaksasi yang tinggi (Clark \& Sunnen, 2004). Respon relaksasi ini mempunyai efek mengurangi ketegangan dan stres dari pikiran seseorang. Pada prinsipnya hypnosis adalah self hypnosis artinya, bahwa semua kegiatan hypnosis adalah kegiatan yang dilakukan oleh klien terhadap dirinya (Nurindra, 2007).

\section{METODE}

Desain penelitian menggunakan one group pre test post test design, populasi dalam penelitian ini adalah seluruh mahasiswa S1 Keperawatan STIKes Buana Husada sebanyak 22 orang. Teknik sampling menggunakan total sampling dengan jumlah 22 mahasiswa. Instrumen yang digunakan adalah kuesioner kecemasan HARS, dan modul self hypnosis. Analisa data menggunakan uji wilcoxon dengan $\alpha(0,05)$. Penelitian dilaksanakan di STIKes Buana Husada Ponorogo. Prosedur penelitian dimulai dengan mengurus perizinan dan persetujuan penelitian kepada Ketua STIKes Buana Husada Ponorogo. Mengurus persetujuan dengan Ketua LPPM STIKes Buana Husada Ponorogo. Pemberian informed consent kepada subyek sebagai persetujuan menjadi responden, setelah disetujui dan ditandatangani oleh responden kemudian kuesioner dibagikan kepada responden untuk diisi. Peneliti melakukan pengukuran respon cemas mahasiswa menggunakan kuesioner. Peneliti melakukan terapi self hypnosis kepada mahasiswa yang dilakukan sebanyak 2 kali pada 1 hari sebelum pelaksanaan Ujian. Sedangkan pengukuran respon cemas mahasiswa dilakukan sebanyak 2 kali, yaitu sebelum 
ujian dan setelah ujian. Pengukuran cemas dilakukan setelah terapi self hypnosis dilakukan oleh mahasiswa. Sebagai evaluasi masing-masing mahasiswa merekam kegiatan self hynosis dirumah masing-masing. Data hasil yang telah terkumpul, dilakukan pengecekan kelengkapan data, diskor, coding, tabulating dan analisis data menggunakan program SPSS 21.

\section{HASIL PENELITIAN}

Tabel Tingkat kecamasan responden sebelum pemberian terapi self hypnosis mahasiswa S1 $1 \quad$ Keperawatan

\begin{tabular}{cccc}
\hline No & Kecemasan & Frekuensi & Persentase \\
\hline 1 & Tidak Cemas & 1 & 5 \\
2 & Cemas Ringan & 8 & 40 \\
3 & Cemas Sedang & 10 & 50 \\
4 & Cemas Berat & 1 & 5 \\
\hline & Jumlah & 20 & 100 \\
\hline
\end{tabular}

Sumber : Data primer

Berdasarkan analisa diatas menunjukkan hasil bahwa sebagian besar kecemasan responden sebelum pemberian self hypnosis kategori cemas sedang sebanyak 10 (50\%) responden, kategori ringan sebanyak 8 (40\%) responden, kategori cemas berat sebanyak 1 (5\%) responden, dan tidak cemas 1 (5\%) responden.

Tabel 2 Tingkat kecamasan responden setelah pemberian terapi self hypnosis mahasiswa S1 Keperawatan

\begin{tabular}{lccc}
\hline No & Kecemasan & Frekuensi & Persentase \\
\hline 1 & Tidak Cemas & 2 & 10 \\
2 & Cemas Ringan & 9 & 45 \\
3 & Cemas Sedang & 8 & 40 \\
4 & Cemas Berat & 1 & 5 \\
\hline & Jumlah & 20 & 100 \\
\hline
\end{tabular}

Sumber : Data primer

Berdasarkan analisa diatas menunjukkan hasil bahwa sebagian besar kecemasan responden setelah pemberian self hypnosis kategori cemas ringan sebanyak 9 (45\%) responden, kategori sedang sebanyak 8 (40\%) responden, kategori cemas berat sebanyak 1 (5\%) responden, dan tidak cemas 2 (10\%) responden.

Tabel 3 Pengaruh self hypnosis terhadap respon cemas mahasiswa S1 Keperawatan pada UHAP KDM STIKes Buana Husada Ponorogo

\begin{tabular}{ccc}
\hline Variabel & Nilai Z & p value \\
\hline Self Hypnosis & -2.143 & 0.032
\end{tabular}

Sumber : Data primer

Hasil analisis menunjukkan bahwa ada pengaruh pemberian Pengaruh self hypnosis terhadap respon cemas mahasiswa S1 Keperawatan pada UHAP KDM. Nilai p value (0.032) menunjukkan ada 
pengaruh pemberian self hypnosis. Sedangkan nilai Z (-2.143) menunjukkan bahwa nilai post lebih kecil dari nilai pre. Hal ini dikarenakan pemberian self hypnosis berhasil secara signifikan menurunkan angka kecemasan mahasiswa.

\section{PEMBAHASAN}

Kecemasan merupakan suatu perasaan subjektif mengenai ketegangan mental yang menggelisahkan sebagai reaksi umum dari ketidakmampuan mengatasi suatu masalah atau tidak adanya rasa aman. Perasaan yang tidak menentu tersebut pada umumnya tidak menyenangkan yang nantinya akan menimbulkan atau disertai perubahan fisiologis dan psikologis (Rochman \& Lur, 2010). Hasil analisa menunjukkan sebagian besar kecemasan responden sebelum pemberian self hypnosis kategori cemas sedang sebanyak 10 (50\%) responden, kategori ringan sebanyak 8 (40\%) responden, kategori cemas berat sebanyak $1(5 \%)$ responden, dan kategori tidak cemas $1(5 \%)$ responden.

Hasil penelitian ini sebagian besar mahasiswa mengalami cemas sedang, hal ini dikarenakan pada UHAP KDM akan diujikan beberapa kompetensi yang harus dikuasai dengan baik oleh mahasiswa, meliputi personal hygiene, eliminasi, aktifitas istirahat dan tidur, rasa aman dan nyaman. Kondisi tersebut tentu menimbulkan kecemasan pada mahasiswa dikarenakan takut salah dalam melakukan praktik sehingga harus mengulang dan kecemasan masing-masing mahasiswa berbeda sesuai dengan koping yang mereka miliki.

UHAP KDM ditujukan untuk memberikan pengalaman belajar bagi mahasiswa. Dalam rangka meningkatkan ketrampilan mahasiswa khususnya terkait mata ajar kebutuhan dasar manusia, maka diperlukan pembelajaran praktek klinik keperawatan. Mata kuliah ini diarahkan untuk memberikan kesempatan kepada para mahasiswa mempraktikkan teori dan konsep yang telah dipelajari di kelas dan diuji coba di laboratorium dibawah pengawasan instruktur laboratorium.

Hasil analisa menunjukkan bahwa sebagian besar kecemasan responden setelah pemberian self hypnosis kategori cemas ringan sebanyak 9 (45\%) responden, kategori sedang sebanyak 8 (40\%) responden, kategori cemas berat sebanyak $1(5 \%)$ responden, dan tidak cemas 2 (10\%) responden. Hal ini menunjukkan adanya perubahan jumlah responden yang sebelum diberi self hypnosis sebagian besar dalam kategori cemas sedang, namun sekarang setelah pemberian self hypnosis sebagian besar dalam kategori cemas ringan.

Menurut Gail \& Stuart (2006) bahwa kecemasan ringan berhubungan dengan ketegangan pada kehidupan sehari-hari dan menyebabkan seseorang menjadi waspada, dan meningkatkan lahan persepsinya. Kecemasan ini dapat memotivasi belajar, dan menghasilkan pertumbuhan dan kreativitas. Kecemasan ringan diperlukan untuk seseorang agar berfungsi dan berespon secara efektif terhadap lingkungan dan kejadian. Seseorang dengan kecemasan ringan dapat dijumpai hal-hal sebagai berikut; persepsi dan perhatian semakin meningkat, mampu mengatasi situasi bermasalah, dapat mengintegrasikan pengalaman masa lalu saat ini dan masa yang akan datang. Hal ini berarti melalui 
perubahan respon cemas mahasiswa menunjukkan bahwa pemberian self hypnosis signifikan berpengaruh terhadap respon cemas mahasiswa.

Hasil analisis wilcoxon menunjukkan bahwa ada pengaruh pemberian Pengaruh self hypnosis terhadap respon cemas mahasiswa S1 Keperawatan pada UHAP KDM. Nilai p value (0.032) menunjukkan ada pengaruh pemberian self hypnosis. Sedangkan nilai Z (-2.143) menunjukkan bahwa nilai post lebih kecil dari nilai pre. Hal ini dikarenakan pemberian self hypnosis berhasil secara signifikan menurunkan angka kecemasan mahasiswa. Namun dari hasil analisis masih cukup banyak mahasiswa dalam kategori cemas sedang, hal ini dimungkinkan beberapa faktor yang mempengaruhi respon cemas diantaranya adalah kurangnya pengetahuan. Sesuai teori dari (Masoumi \& Sharif, 2005) bahwa mahasiswa merasa cemas saat melaksanakan praktik klinik mereka khawatir memberi informasi yang salah kepada pasien sehingga akan merugikan pasien, mahasiswa juga merasa takut gagal dan takut membuat kesalahan dalam memberikan tindakan keperawatan kepada pasien. Hal ini karena kurangnya pengetahuan mahasiswa tentang kompetensi yang diujikan pada saat UHAP KDM. Oleh karena itu untuk mengurangi kecemasan adalah dengan cara memberikan pembekalan dan persiapan yang cukup kepada mahasiswa.

Pemberian Self Hypnosis merupakan teknik hipnosis yang dilakukan tanpa bantuan orang lain. Teknik ini bersifat mandiri dan sangat bagus untuk meningkatkan sistem keyakinan diri (self belief) seseorang. Menurut (Hakim, 2010) bahwa Self hypnosis bertujuan untuk membangun mental pengajar maupun mahasiswa agar memiliki daya dan kekuatan optimal dalam setiap sesi pengajaran yang dilakukan. Para ahli hipnosis telah membuat sebuah metode melakukan self hypnosis secara tepat dan benar. Diharapkan dengan metode tersebut, setiap orang mampu menerapkan hipnosis yang sebenarnya melalui komunikasi dengan alam bawah sadar mereka secara mandiri tanpa bantuan trainer/orang lain sehingga tercipta kondisi yang nyaman dan tenang, sehingga cemas bisa berangsur berkurang.

\section{KESIMPULAN}

Ada pengaruh pemberian self hypnosis terhadap respon cemas mahasiswa S1 Keperawatan pada UHAP KDM. Hal ini menunjukkan bahwa terapi self hypnosis berhasil secara signifikan menurunkan angka kecemasan mahasiswa.

\section{DAFTAR PUSTAKA}

Clark, \& Sunnen. (2004). The Relaxation \& Stress Reduction Workbook ( dan K. B. A. Hamid, A.Y. (ed.)). EGC.

Gail, \& Stuart, W. (2006). Buku Saku Keperawatan Jiwa (3rd ed.). EGC.

Gunawan, A. (2005). Hypnotherapy The Art Of Subconcious Restructuring. PT Gramedia Pustaka.

Hakim, A. (2010). Hypnosis in Teaching. Visimedia. 
Masoumi, \& Sharif. (2005). A qualitative study of nursing student experiences of clinical practice. http://www.biomedcentral.com/1472-6955/4/6.

Nurindra, Y. (2007). Hypnotherapy Fundamental. Yan Nurindra School of Hypnotism.

Rochman, \& Lur, K. (2010). Kesehatan Mental. Fajar Media Press.

Tomb. (2004). Buku Saku Psikiatri. EGC. 